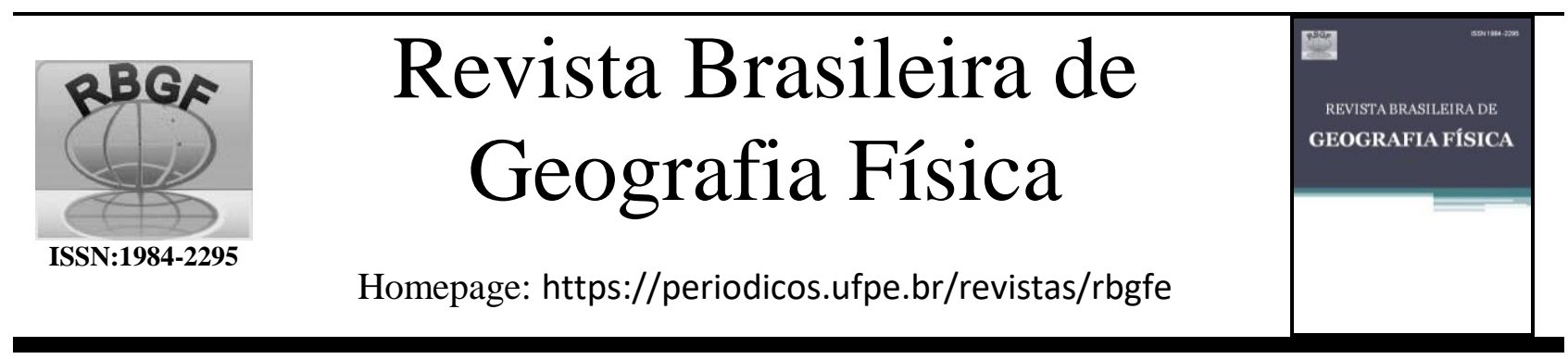

\title{
Forma Da Vertente Como Condição De Contorno Na Instabilidade De Encosta ${ }^{1}$
}

\author{
Felipe Costa Abreu Lopes ${ }^{1}$, Irani dos Santos ${ }^{2}$
}

${ }^{1}$ Doutorando em Geografia pela UFPR, professor do Instituto Federal de Educação Ciência e Tecnologia de São Paulo (IFSP) Câmpus Avançado Jundiaí. (11) 24488500. fcalopes@ ifsp.edu.br (autor correspondente). ${ }^{2}$ Dr. Professor do Departamento de Geografia na Universidade Federal do Paraná (UFPR), Curitiba, Paraná. irani@ufpr.br

Artigo recebido em 15/08/2020e aceito em 05/04/2021

\section{R E S U M O}

Entre os principais motivos para a deflagração dos movimentos de massa estão as características geomorfológicas. A declividade é a característica geomorfológica de maior destaque na literatura, porém outros fatores ambientais influenciam na configuração dos movimentos de massa, mas devido as suas complexidade e incertezas muitos deles não são utilizados, portanto o objetivo desse trabalho foi investigar os efeitos da forma da vertente como condição de contorno de movimentos de massa. O estudo foi realizado na bacia do Gigante com 1,65 km², afluente do rio Jacareí, localizado no município de Antonina - PR. As formas da vertente foram representadas a partir das rupturas de relevo e das áreas de concentração de sedimentos, interpretadas a partir da combinação entre a declividade e os planos e perfis de curvatura. Para servir de comparação foi feita uma simulação de instabilidade usando-se o modelo SHALSTAB e ambos os resultados foram verificados com um inventário de cicatrizes da área em uma matriz de confusão. A utilização das formas de vertente resultou em $71 \%$ de eficiência na indicação de áreas instáveis enquanto a simulação realizada com o modelo SHALSTAB obteve $61 \%$. A maior eficiência alcançada com o primeiro método se justifica por menos exageros e erros na delimitação da instabilidade. Os resultados indicam que a forma da vertente usados em conjunto com a variável declividade diminuem a superestimação da simulação de áreas de instabilidade, evidenciando o potencial de sua utilização para futuros estudos de instabilidade de encosta.

Palavras-chave: Movimentos de massa; Forma da vertente; SHALSTAB.

\section{Strand Shape as Contour Condition in Slope Instability1}

\begin{abstract}
The geomorphological characteristics are among the main reasons for the triggering of mass movements. The slope is the most prominent geomorphological feature mentioned in the literature, however other environmental factors influence the configuration of mass movements, but due to their complexity and uncertainties many of them are neglected, therefore the goal of this study was to investigate the effects of the slope shape as a boundary condition of mass movements. The study was carried out in the $1.65 \mathrm{~km}^{2}$ Gigante basin, a tributary of the Jacareí river, located in Antonina - PR. The slope shapes were represented from the relief ruptures and sediment concentration areas, represented from the combination of slope and planes and profiles curvatures. For comparison, a simulation was performed using the SHALSTAB model and both results were verified with a mass movement inventory of the area in a confusion matrix. The use of slope forms resulted in a efficiency of $71 \%$ while the simulation performed with the SHALSTAB model obtained $61 \%$. The higher efficiency achieved with the first method is justified by fewer exaggerations and errors in the delimitation of instability areas. The results indicate that the slope curvature used together with the slope variable decreases the overestimation of the instability area simulation, highlighting the potential of its use for future slope instability studies.
\end{abstract}

Keywords: Mass movements; Slope curvature; SHALSTAB. 


\section{Introdução}

Estudos sobre a previsão e compreensão dos processos envolvidos na ocorrência de movimentos de massa foram muito realizados durante o século passado (REICHENBACH et al, 2018) devido ao impacto social e econômico causados (Barros et al, 2020 e Tabalipa, 2019) e, com o desenvolvimento cada vez mais veloz e da maior acessibilidade aos computadores, o emprego de modelos matemáticos para se realizar tais pesquisas se tornou mais difundido e continua sendo explorado nas duas primeiras décadas do século XXI por muitos trabalhos presentes na literatura (Zhao e Lu, 2018; e o Intrieri et al, 2019; e o Dikshit et al, 2019 e Prakash et al, 2020). Apesar disso ainda há muitas limitações em sua compreensão, principalmente no que diz respeito ao seu mapeamento preventivo e aos parâmetros e variáveis naturais envolvidos.

Movimentos de massa são resultados da perda do equilíbrio natural e complexo das vertentes controlado pela combinação de inúmeros processos inerentes ao local, que envolvem características geológicas, pedológicas, geomorfológicas, hidrológicas e de uso do solo aliadas às influências externas como volume de precipitação, quantidade de insolação, força dos ventos, presença de vegetação e ações antrópicas (Naidu et al, 2018, Negrini (2018) e Handwerger et al, 2019; e Gonzalez-Ollauri e Mickovski, 2017; e Freires et al, 2020). A grande quantidade de variáveis que podem ser inseridas na determinação da estabilidade, força os pesquisadores a dar mais importância para as que têm maior relevância em seus locais de estudo, fato que se nota com o desenvolvimento de diferentes modelos matemáticos baseados nas características predominantes dos seus respectivos locais de pesquisa. Isso leva à exclusão ou à subestimação de algumas variáveis que podem ser mais relevantes para determinadas particularidades de outros locais, influenciando assim a eficiência dos resultados e restringindo espacialmente a aplicação de modelos (Whiteley et al, 2019). Como a complexidade da dependência entre essas variáveis é muito grande, a escolha e a distribuição espacial dessas é de difícil determinação e muitos dos modelos matemáticos existentes tendem a dar mais importância para certas variáveis em detrimento de outras, o que pode ser verificado com a aplicação de diferentes modelos para uma mesma área de estudo, com os mesmos dados, que ainda assim apresentarão resultados diversos.
São vários os parâmetros e as variáveis naturais que influenciam na estabilidade de encosta. Alguns desses foram já muito explorados na literatura e suas influências no equilíbrio da vertente são conhecidas (a exemplo da declividade e da permeabilidade do solo), por outro lado outros ainda permanecem com sua função pouco definida e muitas vezes não estão diretamente presentes nas pesquisas e nos modelos de instabilidade, apesar de se conhecer sua importância na dinâmica dos processos como, por exemplo, a espacialização da espessura do solo e forma da vertente.

A geomorfologia, interpretada sob a forma da vertente em suas diversas maneiras (curvatura, declividade e orientação) contribui diretamente para a susceptibilidade à instabilidade de qualquer área, pois a atual forma do relevo é o resultado de sua evolução e do delicado equilíbrio que o mantem estável. A forma de uma vertente e seu estado de equilíbrio são interdependentes, ou seja, qualquer mudança em sua forma resulta na alteração do seu equilíbrio e vice-versa. Essa interação faz parte da evolução natural do relevo podendo ocorrer de modo lento e constante ou abruptamente, mudando drasticamente as feições geomorfológicas em um curto período, como na ocorrência de movimentos de massa.

A complexidade natural que envolve os movimentos de massa, do estudo de sua origem, locais de possíveis ocorrências, danos potencias e mapeamento de cicatrizes justifica esse fenômeno ser estudado por tanto tempo, e ainda assim, haver lacunas em seu entendimento. Visando cooperar para aumentar a compreensão sobre esse fenômeno natural, a influência da forma da vertente (plano e perfil de curvatura) como condição de contorno na deflagração e localização de movimentos de massa em regiões de climas úmidos foi o objetivo principal desse artigo.

Revisão Bibliográfica - A declividade é um fator largamente indicado na literatura como de grande relevância em relação a estabilidade de vertentes. Diversos estudos foram realizados mostrando esta influência indicando valores limítrofes e intervalos nos quais os movimentos de massa são mais comuns para diferentes regiões do planeta (Sidle, 1985; Dai et al, 2002, Fernandes et al, 2004; Clerici et al, 2006; De Rose, 2012; Masoumi et al, 2014; Meten et al, 2015; Hamsa et al, 2017; entre outros). 
A relação entre a declividade da encosta e sua susceptibilidade aos movimentos de massa ocorre de modo diretamente proporcional, ou seja, quanto mais íngreme for a vertente, mais favorável à ocorrência desses movimentos (Sidle et al, 1985).

Dai et al (2002) afirmam em trabalho sobre estabilidade de encosta realizado em Hong Kong, que o ângulo de inclinação da vertente é um importante fator em sua estabilidade e, que se o material que a compõe for homogêneo, este ângulo é diretamente proporcional à tendência à ocorrência de movimentos de massa, porém os autores ponderam que outros fatores, como a espessura do solo, também exercem grande influência no equilíbrio natural da vertente. Em seu estudo foi indicado o intervalo entre $35^{\circ}$ e $40^{\circ}$ como o mais representativo para cicatrizes mapeadas.

$\mathrm{O}$ intervalo de declividade no qual se concentram a maior parte dos movimentos de massa varia de acordo com as características locais, a exemplo disso De Rose (2012) em estudo desenvolvido na Nova Zelândia concluiu que $95 \%$ dos escorregamentos de uma região denominada Te Whanga estavam em ângulo de encosta superiores a 24 graus. Fernandes et al (2004) cita estudos realizados no estado do Rio de Janeiro, Brasil, e apontam um intervalo entre os ângulos de declividade de 20 e 29 graus para a ocorrência de escorregamentos.

Meten et al (2015) encontraram valores de declividade entre 30 e $40^{\circ}$ com maior concentração e cicatrizes de movimentos de massa em sua área de estudo na Etiópia, porém destacam que acima de $20^{\circ}$ de declividade a concentração de cicatrizes já é muito elevada.

Hamsa et al (2017) também analisaram o papel da declividade nos movimentos de massa, analisando um mapa inventário com 34 cicatrizes e chegando a um intervalo entre $14^{\circ}$ e $25^{\circ}$ de declividade concentrando $82 \%$ das cicatrizes. Os autores justificam esses resultados como a grande presença de material coluvionar e aluvionar nas áreas que correspondem a esses valores de declividade.

Apesar da relevância dada à declividade como fator para desencadear movimentos de massa, o intervalo numérico não é constante e muitas vezes a declividade sozinha não esclarece a presença desses movimentos e por isso deve ser associada a outros fatores. Neste sentido, Clerici et al (2006) em estudo para desenvolver um modelo estatístico de susceptibilidade aos movimentos de massa, elaboraram um script que analisou um inventário com 1137 cicatrizes e cinco fatores: geologia, orientação da vertente, ângulo da encosta, elevação e a relação entre declividade e acamamento. Seus resultados mostraram que o ângulo da encosta, quando atrelado à geologia da área de estudo, foram os fatores mais relevantes.

Masoumi et al (2014) analisando os efeitos da declividade, orientação da vertente e geologia nos movimentos de massa concluem que para sua área de estudo, as declividades que apresentaram maior concentração de cicatrizes de movimentos de massa estavam entre os intervalos de $0 \%$ e $20 \%$ (entre 0 e aproximadamente 11 graus). Os autores justificam esse resultado inesperado com as características de sua área de estudo (por exemplo a ausência de solo em declividades mais acentuadas) e discutem o uso indiscriminado de parâmetros tidos como altamente influenciáveis na estabilidade de encostas em diferentes áreas de estudo, onde outros parâmetros podem ter maior relevância. Apesar disso, modelos físicos atuais de previsão de áreas instáveis usam a declividade da encosta como fator preponderante em suas equações (LOPES, 2017).

Atualmente, o uso de modelos estatísticos e machine learning estão colocando o fator da inclinação em um papel mais coadjuvante. Analisando mais de uma dezena de variáveis (Meinhardt et al, 2015) indicaram conclusões em seus trabalhos que, estatisticamente, excluem a declividade como grande fator influenciador na ocorrência de movimentos de massa.

Comumente associados à declividade, os diferentes planos e perfis de curvatura têm atuações importantes no equilíbrio natural da vertente, já que influenciam a direção do fluxo dos escoamentos e a acumulação de sedimentos, porém não fazem parte da maioria dos modelos físicos e, estatisticamente, não apresentam tanto peso na relação direta com os movimentos de massa (Chen et al, 2017; Pourghasemi e Rahmati, 2018; e Meinhardt et al, 2015 e Quevedo et al, 2019). Existem infinitas combinações de formas de curvatura na natureza, mas para simplificar elas são classificadas nesse trabalho em curvaturas de perfil (côncavas, convexas e planas), que representam a curvatura da vertente em relação ao seu plano vertical e curvaturas planas (côncavas, convexas e 
planas), que representam a curvatura da vertente baseada em um corte horizontal (Figura 1).

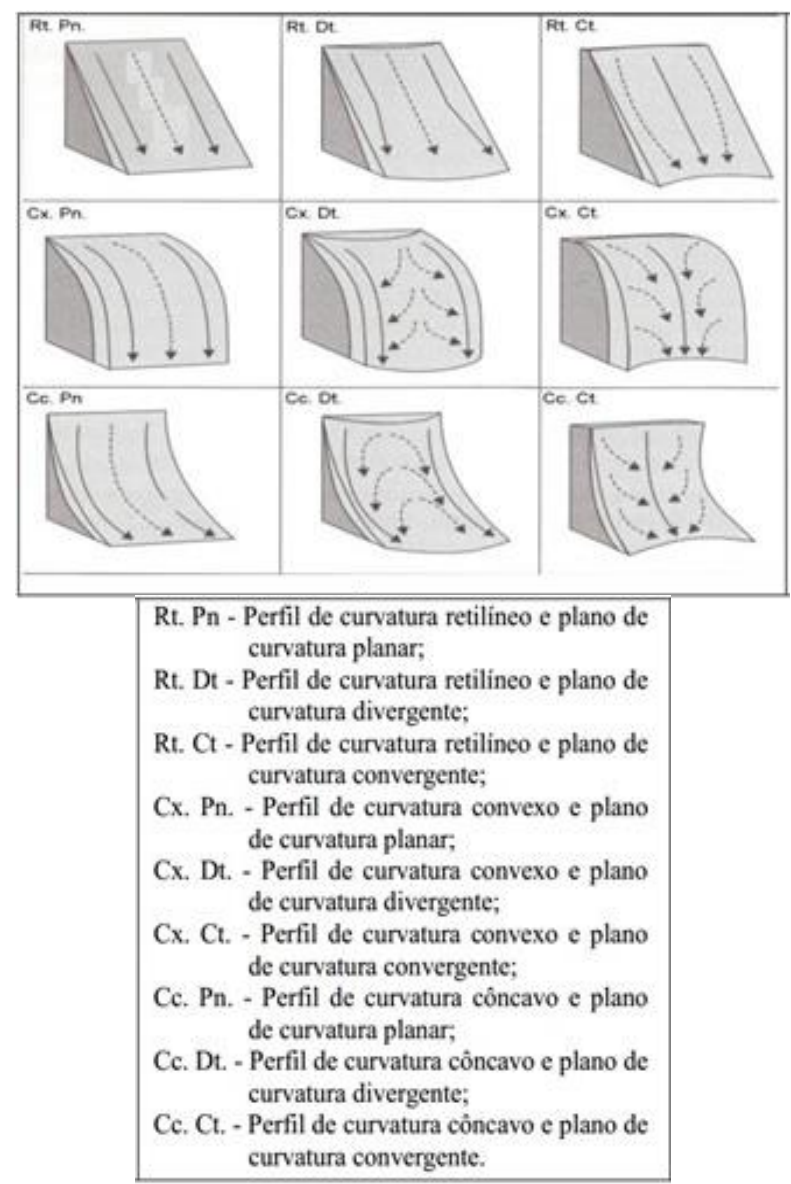

Figura 1 - Esquema de fluxo de água em diferentes tipos de vertente. As setas contínuas representam o fluxo de água no perfil de curvatura e as setas pontilhadas representam o fluxo de água no plano de curvatura. Fonte: Adaptado de Huggett (1975) por Silveira (2010).

É muito difundida na literatura a relação entre a curvatura do relevo e aspectos hidrogeomorfológicos da paisagem como, por exemplo, a concentração do fluxo hídrico, da espessura do solo e, consequentemente, a ocorrência de movimentos de massa, como mostrado por Sidle et al (1985), Reneau et al (1987), Dietrich et al (1995), Fernandes et al (2004), Schulz et al (2008), Montgomery et al (2002), Ohlmacher (2007), Effgen et al (2020) entre outros.

A relação entre as curvaturas e o fluxo hídrico acontece, porque as formas côncavas favorecem a concentração da água e sedimentos originados a montante, enquanto formas convexas favorecem a sua divergência. $O$ acúmulo de sedimentos nas curvaturas predominantemente côncavas ocorre devido a convergência para essas áreas e, quando essa configuração é somada à diminuição da declividade, leva a formação de colúvio, que quando saturados são muito propícios aos movimentos gravitacionais (Dietrich e Dorn, 1984).

As curvaturas convexas, apesar de não serem propicias ao acúmulo de água ainda sofrem com a ocorrência de erosão laminar por escoamento superficial, favorecendo a desagregação e transporte do solo ali presente. Quando analisadas separadamente, as curvaturas côncavas e convexas muitas vezes não têm relação direta com a presença de cicatrizes de movimentos de massa (Rosi et al, 2019; Chen et al, 2017; Pourghasemi e Rahmati, 2018; Meinhardt et al, 2015), mas quando analisadas em conjunto, como parte de um sistema integrado na dinâmica da vertente, podem apresentar relevância.

Áreas de contato abrupto entre curvaturas côncavas e convexas (a montante), denominadas quebras de relevo (Schulz et al, 2008) têm função importante na desestabilização da vertente, porque em suas bases pode ocorrer a exfiltração da água subterrânea que causa sua erosão, com chances de levar ao solapamento de seus sopés, consequente perda de sustentação e de estabilidade do material a montante. Essas rupturas de relevo são as áreas de declividade acentuadas somadas aos planos e perfis de curvatura retilíneos e convexos que se situam a montante de áreas de concentração de colúvio identificadas por curvaturas côncavas. $\mathrm{O}$ fluxo de água acumulado na vertente, e que se infiltra nas áreas côncavas de menor declividade, exfiltra na área de contato entre as curvaturas convexas e côncavas a jusante facilitando a erosão e a instabilidade (Figura 2). Regmi e Walter (2020) usando o índice de rugosidade, que expressa as mudanças na forma do relevo dentro de uma janela de amostragem, também identificaram uma relação direta entre essas mudanças geomorfológicas e a ocorrência de movimentos de massa.

Montgomery et al (2002), em estudo prático com a aplicação e piezômetros em uma vertente côncava verificaram que as áreas de início de movimentos de massa podem estar associadas com a exfiltração de água a partir de rochas expostas sobre solos coluvionares. Isso mostra mais um indício da influência da mudança de curvatura e sua relação com a estabilidade da 
vertente, já que as rochas expostas (ou áreas com solos mais rasos) estão presentes em regiões com curvatura convexa e as áreas de colúvio mais espesso em regiões de curvatura côncava.

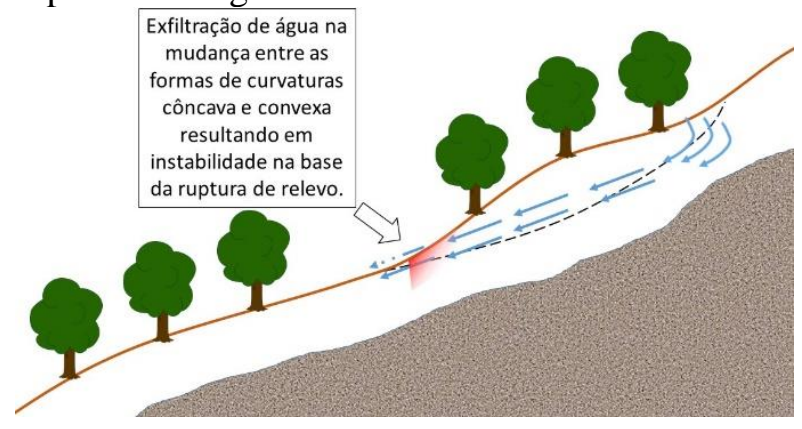

Figura 2 - Ilustração demonstrando a exfiltração da água em área de contato entre curvaturas côncavas e convexas. A área de exfiltração (em vermelho) representa a região que vai sofrer mais erosão e consequente maior instabilidade. A linha pontilha representa um teórico plano de falha.

Ohlmacher (2007) em estudo sobre a relação entre os planos de curvatura e a ocorrência de movimentos de massa afirma, baseado em dados estatísticos e na literatura, que as curvaturas planas (a jusante de áreas de curvatura côncavas) são as mais propícias aos movimentos de massa. Ao contrário de outros autores, ele identifica as áreas côncavas como mais estáveis que as retilíneas porque, por terem maior espessura de solo, têm também maior coesão e por isso acabam sendo mais estáveis do que as áreas de curvatura retilínea, que não acumulam a mesma quantidade de material e por isso tendem a se movimentar antes quando expostas aos mesmos fatores externos (volume de precipitação, por exemplo).

Reneau et al (1987) realizaram amplo levantamento na literatura sobre a relação das áreas de curvatura côncava (hollows) com a ocorrência de movimentos de massa. Os autores discutem sobre o papel das áreas côncavas como fonte de material para os movimentos de massa e estabelecem uma relação entre o tamanho da área de drenagem e a ocorrência de movimentos de massa, afirmando que quanto menor a área de drenagem, maiores as chances da ocorrência desses movimentos, sendo os hollows e side slopes (termos similares à bacia de zero ordem) os mais propensos a instabilidade. Recentemente os trabalhos de Zhang et al (2019) e Wang et al(2017) corroboram com a mesma relação entre a presença de hollows e sua relação com movimentos de massa.
A localização dos locais de exfiltração de água não é fixa na paisagem. Ela se modifica de acordo com as mudanças na quantidade de água recebida pela vertente podendo migrar tanto para montante (precipitação ou degelo) quanto para jusante (períodos de seca) de um ponto conhecido. Isso ocorre pelo escoamento superficial por saturação do solo, que é mais intenso em períodos de grandes volumes de precipitação e acaba unindo-se ao canal de primeira ordem, criando uma continuidade do fluxo e prolongando esses canais em direção à montante. Esse escoamento, quando conectado ao canal de drenagem, passa a fazer parte dele e essa área de interação hidrogeomorfológica entre a vertente e o início do escoamento em canais é denominada de bacia de zero ordem (Tsukamoto e Minematsu, 1987).

As bacias de ordem zero ocorrem tipicamente em vertentes com plano de curvatura côncavo e o escoamento superficial pode ser gerado por saturação do solo ou por exfiltração da água a partir de fissuras nas rochas e mudanças na curvatura. Essas bacias podem contribuir para o prolongamento do início do canal de primeira ordem ou para escoamentos nas vertentes laterais dos vales que eventualmente se unam aos canais da rede de drenagem já estabelecida.

De acordo com Tsukamoto e Minematsu (1987) as áreas das bacias de zero ordem são locais mais sujeitos à ocorrência de escorregamentos pois geralmente são áreas de transição de tipos de solo (solo residual para colúvio), o que permite maior acúmulo de água subsuperficial em decorrência de horizontes com diferentes permeabilidades. São também áreas com presença de inflexão topográfica (mudança de perfil de curvatura, Figura 3).

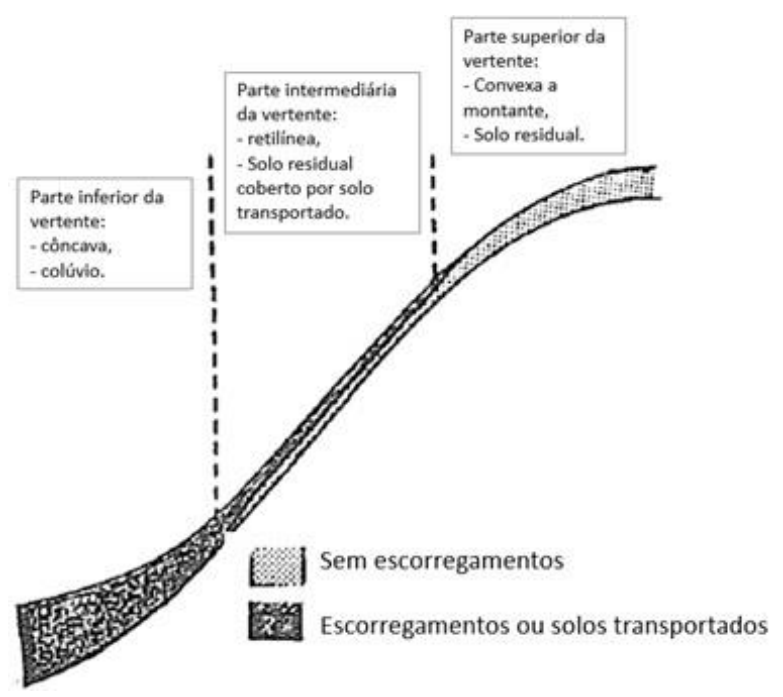


Figura 3 - Esquema mostrando a distribuição de solos em uma vertente de bacia de zero ordem. Adaptado de Tsukamoto e Minematsu (1987).

As inflexões topográficas que apresentam perfis de curvatura com declividades mais acentuadas em contato com declividades mais suaves são chamadas por Tsukamoto e Minematsu (1987) de frentes de erosão. Essas são áreas mais propícias a desencadear escorregamentos a partir da exfiltração do escoamento subsuperficial no contato das duas curvaturas, causando a erosão da base da vertente a montante resultando no seu solapamento. Essa ideia corrobora com Dunne (1980) e Gordon et al (2010) quando afirmam que as regiões de exfiltração na vertente são áreas onde ocorre a erosão a montante, que pode desestabilizar a vertente; também concorda com Schulz et al (2008) que afirmam que as quebras de relevo (similares às frentes de erosão denominadas por Tsukamoto e Minematsu, 1987) são importantes na instabilidade da encosta.

Com a finalidade de compreender mais a respeito da dinâmica e do processo da formação de áreas instáveis em ambientes tropicais, além de melhorar suas representações, diferentes variáveis hidrogeomorfológicas devem ser estudadas visando o desenvolvimento ou a modificação no modo como as áreas de instabilidade são previstas para esses ambientes.

Dessa maneira, a relação da forma da vertente (representada pelas mudanças de curvaturas) como condição de contorno à declividade para a ocorrência de movimentos de massa é apresentada com o objetivo de aprimorar o entendimento dos processos hidrogeomorfológicos envolvidos na espacialização desses eventos na Serra do Mar, e assim permitir mapear com mais precisão as áreas e os locais suscetíveis à ocorrência de movimentos de massa a partir da adoção de mais um parâmetro aos modelos e equações de fator de segurança existentes.

\section{Método}

A área de estudo dessa pesquisa é uma subbacia da bacia do Jacareí e, que foi nomeada bacia do Gigante (Figura 4). A bacia do rio Jacareí ocupa partes dos municípios de Morretes e Paranaguá, enquanto sua sub-bacia do Gigante está inserida totalmente no município de Paranaguá.

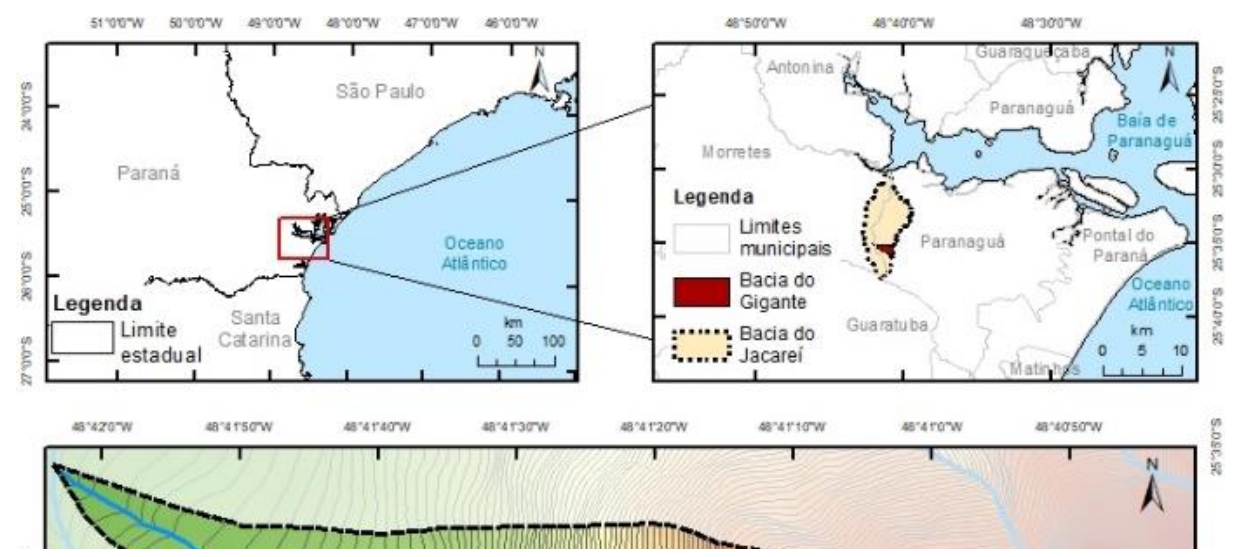

Figura 4 - Localização da bacia do Gigante no litoral paranaense.

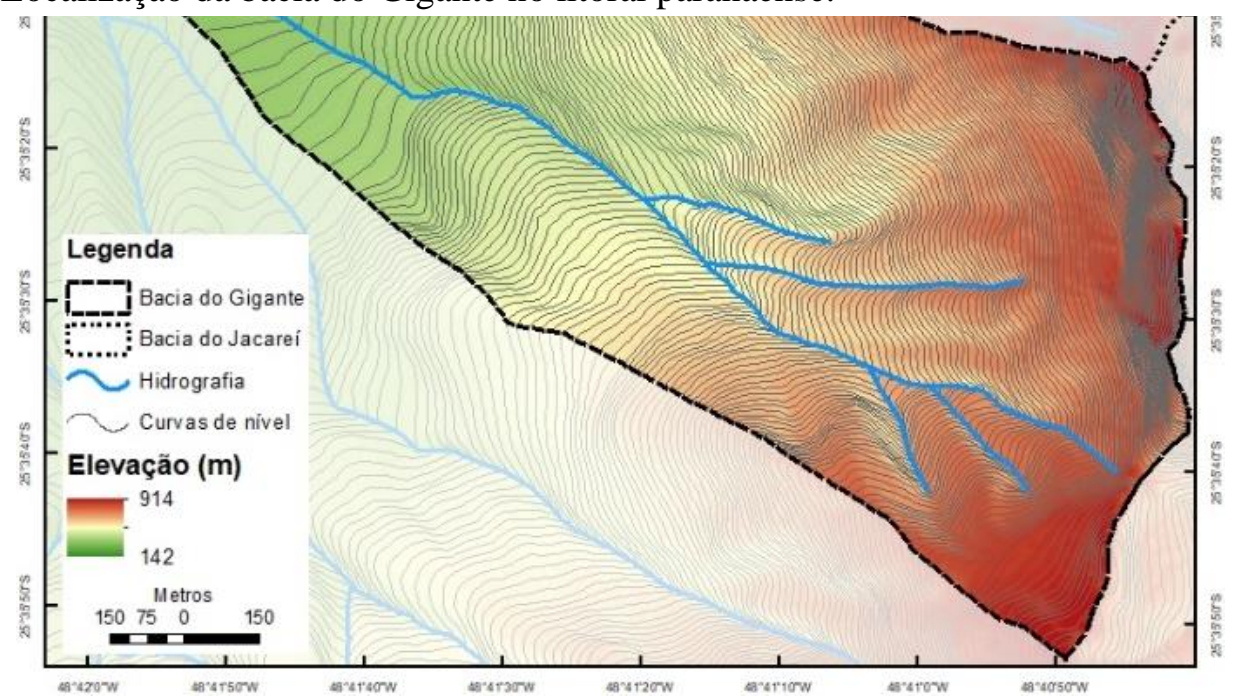

Felipe Costa Abreu Lopes., F., C., A. Santos., I. 
Foi utilizado o software SAGA na geração da declividade (Figura 5) e dos dados de plano e perfil de curvatura (Figura 6) a partir das informações topográficas originadas de um modelo digital de terreno (MDT), gerado com a curvas de nível obtidas de carta topográfica em escala 1:25000.

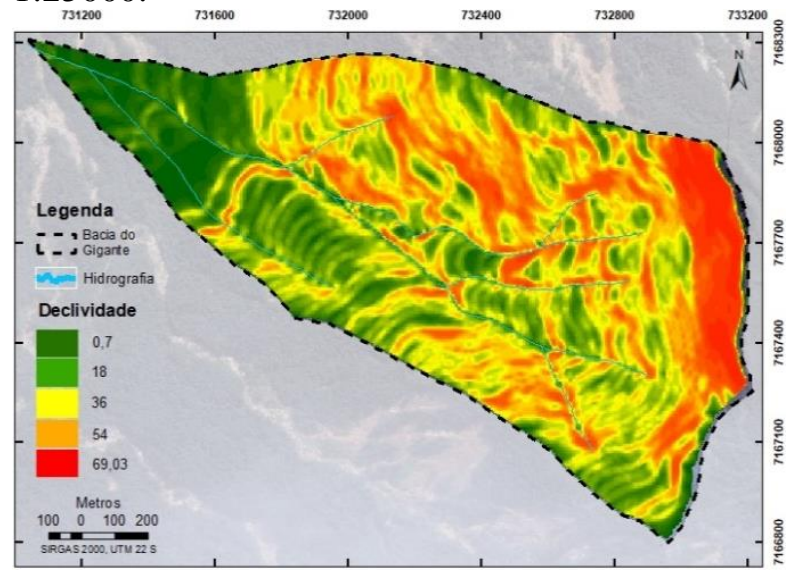

Figura 5 - Representação da declividade da Bacia do Gigante
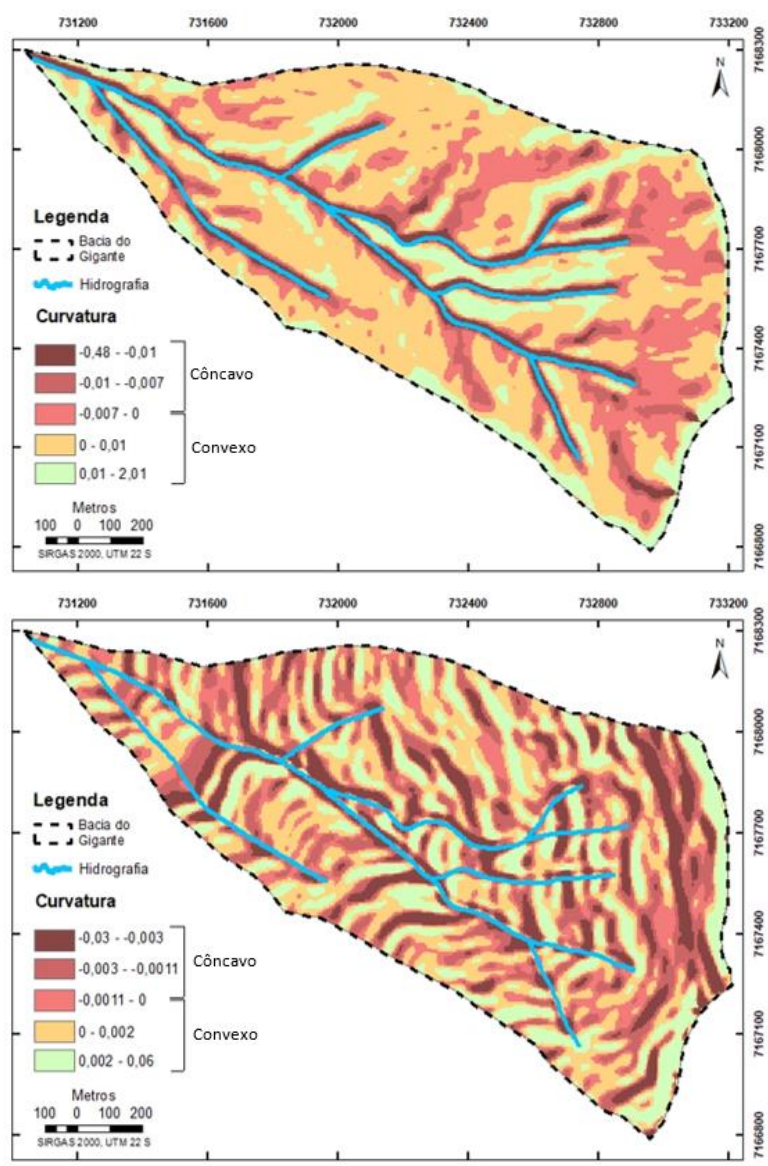

Figura 6 - Representações de plano (A) e perfil (B) de curvaturas.
Os planos e perfis de curvaturas foram calculados usando-se uma janela de $5 \times 5$ pixels. Essa dimensão foi escolhida a partir de testes com diferentes tamanhos de janelas, sendo o tamanho escolhido, a janela mínima a mostrar os dados de curvatura com continuidade e não apresentar grandes generalizações nas vertentes. Janelas de tamanho mais reduzido não foram utilizadas pois em alguns locais das vertentes, o espaço entre duas curvas de nível é maior do que o tamanho da janela, o que leva à criação de descontinuidades na representação das curvaturas resultando, em alguns casos, em classificações errôneas nos valores de planos e perfis. A Figura 7 mostra a comparação entre uma janela com $3 \times 3$ pixels e outra com $5 \times 5$ pixels na classificação das curvaturas. É possível verificar que a primeira gera descontinuidades e inversões errôneas na classificação, que podem ser verificadas pelas curvas de nível.
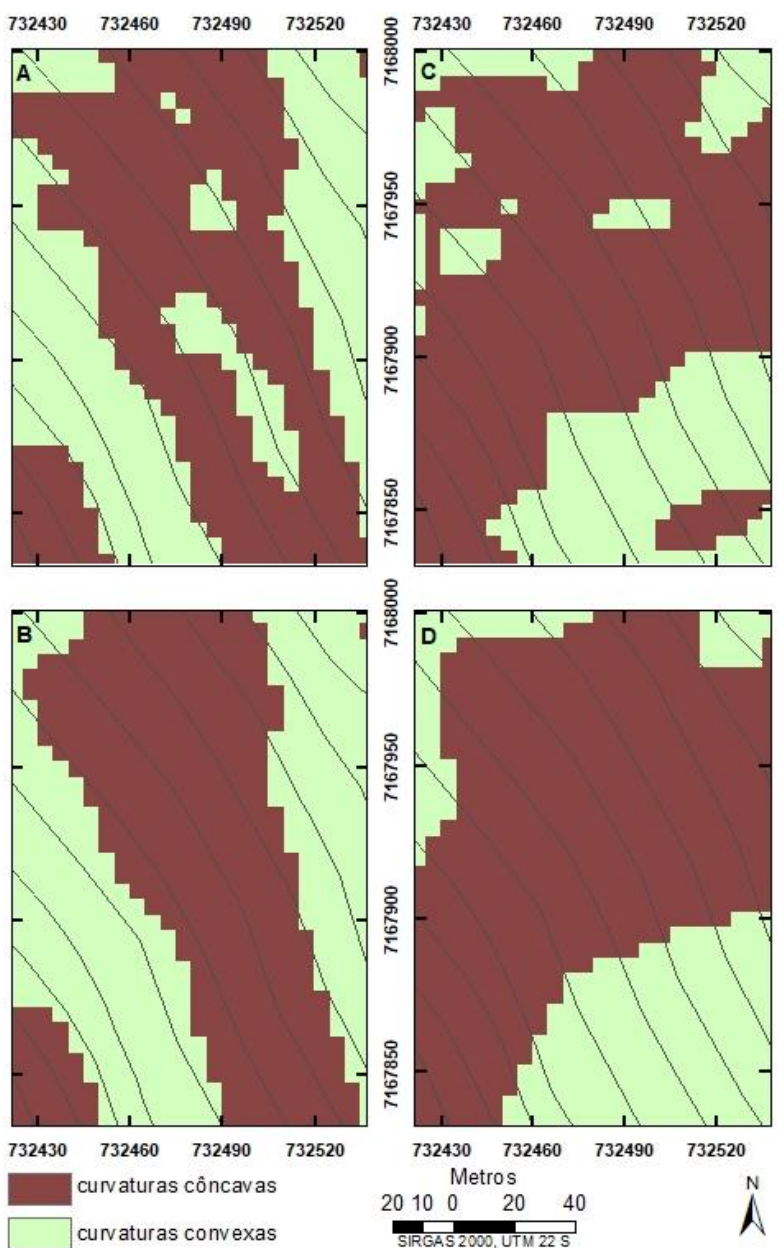

Figura 7 - Influência de diferentes raios da janela de cálculo de curvaturas. A: perfil de curvatura com base em janela de $3 \times 3$ pixels; B: perfil de curvatura com base em janela de $5 \times 5$ pixels; C: plano de curvatura com base em janela de $3 \times 3$ 
pixels e D: plano de curvatura com base em janela de $5 \times 5$ pixels.

As informações de perfil e plano de curvaturas obtidas foram analisadas com os dados de ocorrência de movimentos de massa associados à presença de cicatrizes de movimentos de massa, mapeadas na área de estudo no trabalho de Bueno et al (2015). Os resultados foram cruzados a fim de se encontrar a conexão entre curvatura da vertente e presença de movimentos de massa. As analises foram feitas utilizando-se os softwares ArcGIS 10.1 e Excel 2013.

As áreas com presença mais significativa de colúvio em uma vertente (denominadas aqui concentração de colúvio) ocupam porções do relevo com declividade pouco acentuada e de valores de curvatura côncava. Baseado nessas premissas, as áreas de concentração de colúvio foram mapeadas segundo essas duas características geomorfológicas: declividade e curvatura.

A declividade usada para delimitar a presença de colúvio foi baseada nos valores de ângulo de atrito encontrados na Serra do Mar para a classe de solo presente na área (cambissolo associados a neossolos) nos trabalhos de Kozciak (2005) e Folador (2015) e nos valores de declividade a partir dos quais foi constatada a presença de rochas expostas por meio de imagens de satélite provenientes do Google Earth.

O ângulo de atrito interno do solo representa a sua declividade máxima de repouso (sem a influência da vegetação), sendo assim, valores abaixo do estipulado pelo ângulo de atrito são tidos como estáveis. Dessa maneira o intervalo de declividade de interesse para a identificação de concentração de colúvio passiveis ao movimento de massa está entre o valor do ângulo de atrito e o valor de declividade das primeiras rochas expostas identificadas nas imagens de satélite.

A representação da curvatura das concentrações de colúvio passível de movimento de massa tais quais baseadas nos trabalhos de Dietrich e Dorn (1984), Dietrich et al (1995) e Schulz et al (2008), Zhang et al (2019) e Wang et al (2017), são áreas descontínuas na vertente e em locais de acumulação de material, identificadas pela sua curvatura côncava e declividades mais baixas. Desse modo os planos e perfis de curvaturas côncavos foram combinados com os valores de declividade para gerar as suas representações (Tabela 1).

\begin{tabular}{|c|c|c|}
\hline Descrição & Valor & Fonte \\
\hline $\begin{array}{c}\text { Intervalo de } \\
\text { declividade } \\
\text { para a } \\
\text { acumulação de } \\
\text { colúvio }\end{array}$ & $20,50^{\circ}-40^{\circ}$ & $\begin{array}{c}\begin{array}{c}\text { Kozciak } \\
(2005),\end{array} \\
\text { Folador } \\
(2015) \text { e } \\
\text { imagens de } \\
\text { satélite. }\end{array}$ \\
\hline $\begin{array}{c}\text { Plano e perfil } \\
\text { de curvatura } \\
\text { côncavos }\end{array}$ & $\begin{array}{l}\text { Planos e } \\
\text { perfis com } \\
\text { valores } \\
\text { negativos }\end{array}$ & $\begin{array}{c}\text { Carta } \\
\text { topográfica }\end{array}$ \\
\hline
\end{tabular}

Tabela 1 - Identificadores para delimitar a presença de colúvio na vertente.

As rupturas de relevo foram identificadas pelas áreas inclinadas com planos e perfis de curvatura retilíneos e convexos (Tabela 2), que se situam a montante das áreas de concentração de colúvio. Dessa maneira, esses valores de curvatura foram combinados com o mesmo intervalo de declividade delimitado para a presença de colúvio. Assim foi possível identificar a influência da variação da curvatura na presença dos movimentos de massa.

\begin{tabular}{ccc}
\hline Descrição & Valor & Fonte \\
\hline $\begin{array}{c}\text { Intervalo de } \\
\text { declividade } \\
\text { para a }\end{array}$ & & $\begin{array}{c}\text { Kozciak } \\
(2005),\end{array}$ \\
$\begin{array}{c}\text { presença de } \\
\text { rupturas de } \\
\text { relevo }\end{array}$ & $20,50^{\circ}-40^{\circ}$ & $\begin{array}{c}\text { Folador } \\
(2015) \mathrm{e}\end{array}$ \\
\hline $\begin{array}{c}\text { Planos e } \\
\text { perfis de } \\
\text { curvatura } \\
\text { satélite }\end{array}$ \\
$\begin{array}{c}\text { retilíneos e } \\
\text { convexos }\end{array}$ & $\begin{array}{c}\text { Planos e } \\
\text { valores com } \\
\text { valositivos }\end{array}$ & $\begin{array}{c}\text { Carta } \\
\text { topográfica }\end{array}$ \\
\hline
\end{tabular}

Tabela 2 - Indicadores para delimitar a presença de rupturas de relevo 
O fluxograma a seguir ilustra os passos para o mapeamento das áreas de colúvio e de ruptura de relevo (Figura 8).

Afim de avaliar o método proposto neste trabalho com um modelo consagrado na literatura, os resultados da relação entre os planos e perfis de curvatura e o mapeamento das cicatrizes de movimento de massa (Bueno et al, 2015) foram comparados com uma simulação realizada pelo modelo SHALSTAB (Montgomery e Dietrich, 1994) para a mesma área. para compara-lo com a influência das curvaturas na ocorrência de movimentos de massa.

Os valores dos dados usados para a criação do cenário de instabilidade (Tabela 3) foram retirados de trabalhos realizados na região da área de estudo por Kozciak (2005) e Folador (2015) e por levantamentos de campo.

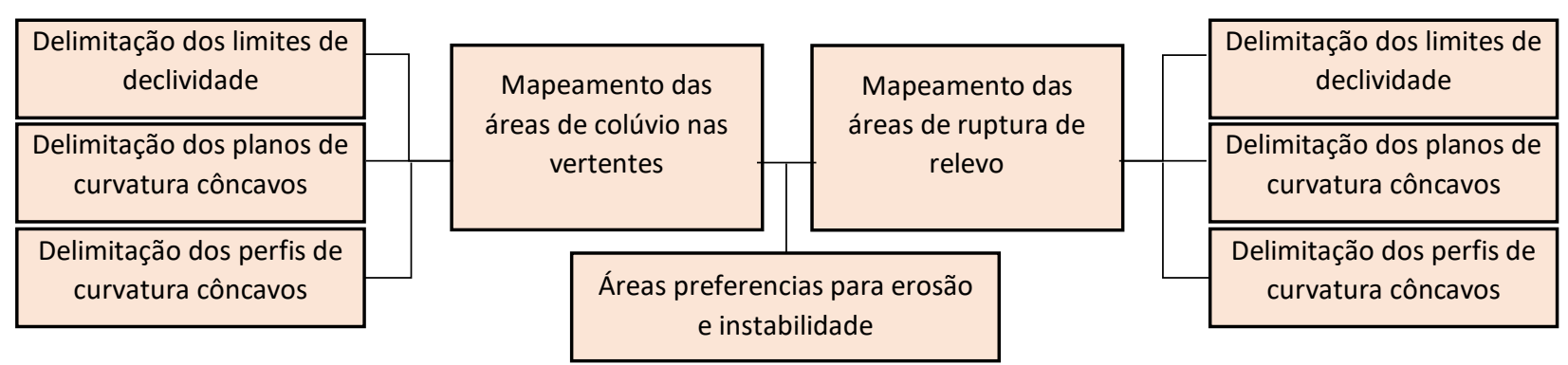

O SHALSTAB é um modelo de previsão

Figura 8 - Fluxograma esquemático para a delimitação das áreas de colúvio e de rupturas de vertente.

de áreas instáveis, distribuído e determinístico, isto é, fisicamente baseado e com um resultado para cada combinação específica das variáveis de entrada para cada pixel da bacia hidrográfica. Combina em sua teoria o modelo de vertente infinita, baseado na teoria de cisalhamento da Lei de Mohr-Coloumb, e um modelo hidrológico de estado uniforme, que resultam no valor do logaritmo em base 10 da relação entre a quantidade de precipitação e a transmissividade do solo na seguinte equação:

$\frac{q}{T}=\frac{b}{a} * \operatorname{sen} \theta *\left[\frac{\rho_{s}}{\rho_{w}} *\left(1-\frac{\tan \theta}{\tan \phi}\right)+\frac{c}{\cos ^{2} \theta * \tan \phi * \rho_{w} * g * z}\right]$

Onde: $q$ é a precipitação, $T$ a transmissividade do solo, $\rho_{s}$ representa o peso específico do solo, $\rho_{w}$ significa o peso específico da água, $c$ representa a coesão do solo, $\phi$ é o ângulo de atrito interno e $\theta$ é a declividade da encosta, $b$ é a resolução espacial, $a$ é a área de contribuição, $g$ é o valor da gravidade e $z$ a espessura do solo.

Esse modelo foi escolhido baseado em Martins et al (2017), que afirmam que o modelo físico mais usado em trabalhos sobre instabilidade de encosta no Brasil é o SHALSTAB. Por ser um modelo amplamente usado e, portanto, muito bem compreendido, optou-se por usá-lo nesta pesquisa

\begin{tabular}{|c|c|c|}
\hline Parâmetro/variável & Valor & Fonte \\
\hline $\begin{array}{l}\text { Peso específico do } \\
\text { solo saturado } \\
\left(\mathrm{ps}, \mathrm{kg} / \mathrm{m}^{3}\right)\end{array}$ & 1730 & Kozciak (2005) \\
\hline $\begin{array}{l}\text { Peso específico da } \\
\text { água }\left(\mathrm{pw}, \mathrm{kg} / \mathrm{m}^{3}\right)\end{array}$ & 1000 & Literatura \\
\hline Coesão $(\mathrm{c}, \mathrm{kPa})$ & 17 & Folador (2015) \\
\hline $\begin{array}{l}\text { Declividade } \\
(\theta, \text { grau })\end{array}$ & MDT & $\begin{array}{c}\text { Carta } \\
\text { topográfica }\end{array}$ \\
\hline $\begin{array}{l}\text { Área de } \\
\text { contribuição } \\
\text { específica }\left(\mathrm{m}^{2} / \mathrm{m}\right)\end{array}$ & MDT & $\begin{array}{c}\text { Carta } \\
\text { topográfica }\end{array}$ \\
\hline $\begin{array}{l}\text { Ângulo de atrito } \\
(\phi, \text { grau })\end{array}$ & 23,5 & Folador (2015) \\
\hline $\begin{array}{l}\text { Espessura média do } \\
\text { solo }(\mathrm{z}, \mathrm{m})\end{array}$ & 6 & $\begin{array}{l}\text { Levantamento } \\
\text { em campo }\end{array}$ \\
\hline
\end{tabular}

Tabela 3 - Valores de entrada usados no modelo SHALSTAB.

Os valores geotécnicos de Folador (2015) foram retirados de diferentes pontos da bacia do Jacareí (da qual a bacia do Gigante é sub-bacia) e analisados em laboratório para a obtenção dos valores de coesão, peso especifico do solo e ângulo de atrito para diferentes classificações de solo identificadas na bacia e a espessura do solo é o seu valor médio obtido nesse trabalho por medições em 
campo realizadas em campanhas entre os anos de 2016 e 2018.

Ambos os resultados obtidos entre a relação das curvaturas com as cicatrizes dos movimentos de massa e a simulação do SHALSTAB foram analisados de acordo com uma matriz de confusão (Tabela 4)

\begin{tabular}{|c|c|c|c|c|}
\hline Classe & $\begin{array}{c}\text { Pixels } \\
\text { instáveis }\end{array}$ & $\begin{array}{c}\text { Pixels } \\
\text { estáveis }\end{array}$ & $\begin{array}{l}\text { Eficiência } \\
\text { da classe }\end{array}$ & $\begin{array}{c}\text { Eficiência } \\
\text { total }\end{array}$ \\
\hline $\begin{array}{l}\text { Áreas } \\
\text { instávei } \\
\text { s }\end{array}$ & $\begin{array}{l}\text { Verdadei } \\
\text { ro } \\
\text { positivo } \\
(\mathrm{vp} 1)\end{array}$ & $\begin{array}{l}\text { Falso } \\
\text { positivo } \\
\text { (fp2) }\end{array}$ & $\begin{array}{c}\mathrm{vp} 1 / \\
(\mathrm{vp} 1+\mathrm{fp} 2)\end{array}$ & $(\operatorname{vp} 1+\mathrm{vp} 2)$ \\
\hline $\begin{array}{l}\text { Áreas } \\
\text { estáveis }\end{array}$ & $\begin{array}{c}\text { Falso } \\
\text { positivo } \\
(\mathrm{fp} 1)\end{array}$ & $\begin{array}{c}\text { Verdadei } \\
\text { ro } \\
\text { positivo } \\
\text { (vp2) }\end{array}$ & $\begin{array}{c}\mathrm{vp} 2 / \\
(\mathrm{vp} 2+\mathrm{fp} 1)\end{array}$ & \\
\hline
\end{tabular}

Tabela 4 - Esquema de matriz de confusão binária.

\section{Resultados e discussão}

Os planos de curvatura, à primeira vista, representam bem o padrão do formato das cicatrizes dos movimentos de massa verificadas na área de estudo e em outros estudos na Serra do Mar (Fernandes et al 2004; Kozciak ,2005; Folador ,2015 entre outros), com um desenvolvimento latitudinal mais pronunciado dando origem ao seu formato mais alongado (na direção divisor de águas $\rightarrow$ fundo de vale) e guiando a direção do fluxo hídrico governado pela gravidade. A Figura 9 ilustra esse processo.

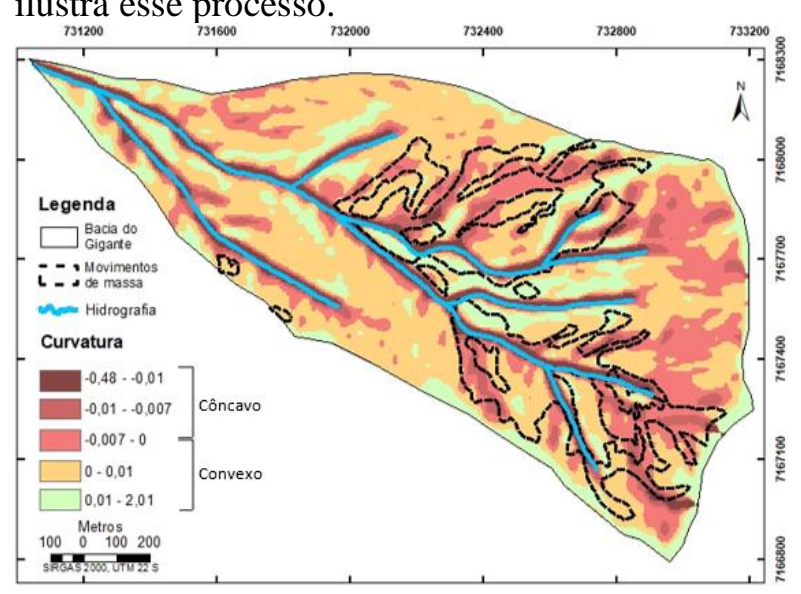

Figura 9 - Plano de curvatura côncavo e cicatrizes de movimentos de massa.
Visualmente as regiões de plano de curvatura côncavo parecem se encaixar bem com as cicatrizes dos movimentos de massa mapeadas para a bacia do Gigante. Além de coincidirem espacialmente, as áreas que representam as concavidades se combinam mais harmonicamente com os formatos reais das cicatrizes, porém muitas dessas áreas estão representadas fora das cicatrizes mapeadas, o que corrobora para a baixa taxa de sucesso nas relações entre curvaturas e movimentos de massa (Chen et al, 2017; Pourghasemi e Rahmati, 2018 e Meinhardt et al, 2015).

Neste sentido, destaca-se que essas cicatrizes resultam de um único evento, podendo ser entendido como sendo um resultado único e caótico, ao passo que outro evento, mesmo que da mesma intensidade, provocaria um arranjo espacial diferente de cicatrizes, o que mudaria a eficiência de qualquer modelo de previsão, já que esse modelo seria aplicado com uma mesma base de dados que levaria sempre a um mesmo resultado.

Outra ponderação que deve ser levada em consideração é que as áreas demarcadas como côncavas podem ter se movimentado em um evento pretérito e, no momento congelado pelo inventário de cicatrizes apresentado, essas áreas ainda não teriam material suficiente para ser deslocado. Além dos argumentos expostos, destaca-se que apenas a variável curvatura da vertente está sendo avaliada, o que naturalmente trará uma eficiência menor e mais limitada aos resultados do que um modelo físico mais completo.

Apesar de a análise visual da relação entre os planos de curvatura e as cicatrizes dos movimentos de massa parecer, num primeiro momento, fazer sentido, as análises gráficas e estatísticas a seguir mostram que essa relação existe e tem potencial para ser mais explorada.

A análise gráfica da concentração dos pixels de plano de curvatura de toda a bacia do Gigante e dos pixels representativos das áreas de movimentos de massa apresentara relação direta com a concentração de cicatrizes (Figura 10). Essa relação era esperada, já que os valores negativos representam os planos de curvatura côncavos que, segundo exposto na revisão bibliográfica e corroborando com Dunne (1980), Tsukamoto e Minematsu (1987), Reneau et al (1987), Gordon et al (2010) e Effgen et al (2020) são os locais de maior concentração de fluxo, acumulando maior 
quantidade de água e sedimentos e consequentemente mais propícios à instabilidade.

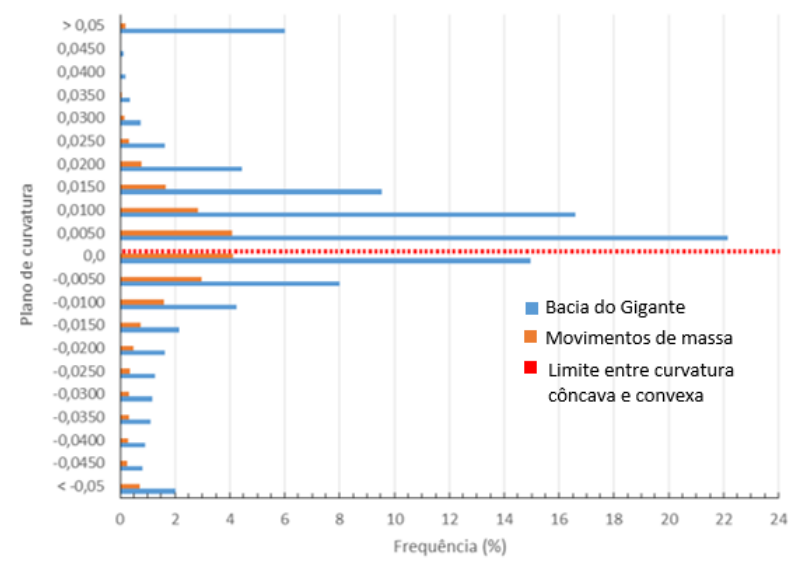

Figura 10 - Relação entre a concentração dos pixels de plano de curvatura para a bacia do Gigante e para os movimentos de massa.

As linhas laranjas mostram duas relações diretamente proporcionais entre os movimentos de massa e plano de curvatura côncavo. A primeira é a maior representatividade de áreas côncavas em detrimento das áreas convexas nas áreas de deslizamento; a segunda está relacionada ao valor da curvatura, que quanto mais distante do zero (em direção aos valores negativos) maior a concavidade, o que mostra que as curvaturas côncavas, além de serem predominantes nas áreas instáveis, têm uma gama de representação maior, partindo de curvaturas quase retilíneas até as concavidades mais acentuadas. As curvaturas convexas, apesar de presentes nas áreas de cicatrizes, apresentam valores mais discretos, o que mostra que elas são mais próximas de planos de curvatura retilíneo e não têm representatividade significante de movimentos de massa em locais com convexidades muito acentuadas (Tabela 5).

\begin{tabular}{ccc|cc}
\hline & \multicolumn{2}{c|}{ Bacia do Gigante } & \multicolumn{2}{|c}{$\begin{array}{c}\text { Movimentos de } \\
\text { massa }\end{array}$} \\
\hline Total & 64133 & 100 & 14335 & 100 \\
Pexels & $\begin{array}{c}\text { Porcenta- } \\
\text { gem (\%) }\end{array}$ & Pixels & $\begin{array}{c}\text { Porcenta- } \\
\text { gem (\%) }\end{array}$ \\
Côncavo & 25916 & 40,41 & 7827 & 54,60 \\
Convexo & 37940 & 59,16 & 6457 & 45,04 \\
Retilíneo & 277 & 0,43 & 51 & 0,36 \\
\hline
\end{tabular}

Tabela 5 - Relação entre plano de curvatura na bacia do Gigante e nas áreas de movimentos de massa.

Apesar de a bacia do Gigante ter a maioria de suas vertentes representadas por curvaturas convexas, seguidas das curvaturas côncavas e retilíneas, as áreas de movimentos de massa têm representatividade maior nos planos de curvatura côncavos. Além da maior representatividade, os valores de concavidade presentes nas áreas de movimento de massa são maiores do que os que representam a convexidade do terreno, isto é, as áreas côncavas têm uma variação de curvatura maior enquanto as áreas convexas têm valores mais baixos, o que mostra que mesmo com $45,04 \%$ das áreas de movimentos de massa, essas curvaturas são muito próximas às formas retilíneas. A relação de grandeza entre os valores de concavidade e convexidade dos planos de curvatura para as cicatrizes de movimentos de massa apresentam valores de concavidade, em média, 87,5\% superiores às convexidades, evidenciando o maior peso das áreas côncavas.

Ao contrário dos planos de curvatura, os perfis de curvatura não mostraram uma relação clara com a presença de cicatrizes de movimentos de massa. A correlação visual entre os perfis côncavos e convexos foram praticamente inexistentes, mostrando que esse tipo de curvatura não influencia diretamente na configuração dos movimentos de massa, em especial na representação de seu formato (Figura 11).

A observação do gráfico comparativo entre os pixels representativos da bacia do Gigante e os representativos dos movimentos de massa, também não traz à tona uma relação visível, em primeira análise, entre os perfis de curvatura e as cicatrizes mapeadas. Essa falta aparente de relação se estende para os valores relativos às concavidades e convexidades, os quais não mostram predominância de nenhuma das duas feições na associação com os movimentos de massa (Figura 12). 
Figura 11 - Perfis de curvatura e cicatrizes de movimentos de massa.

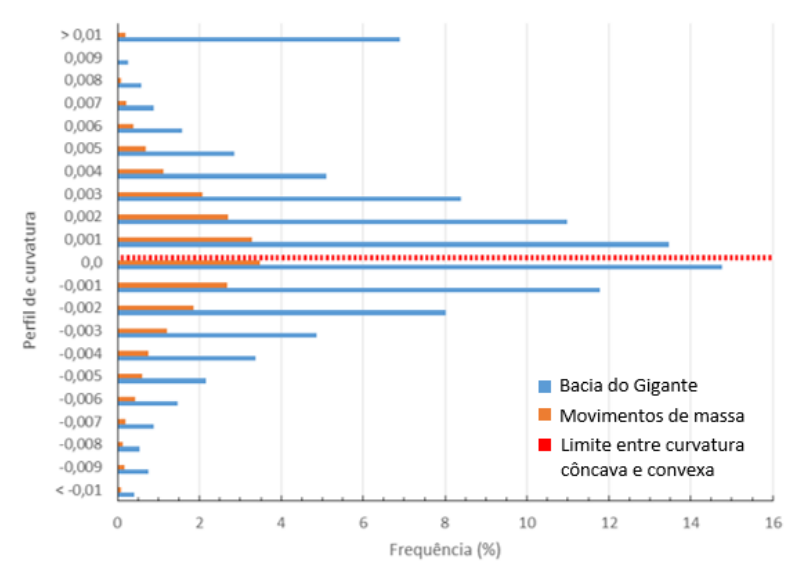

Figura 12 - Relação entre a concentração dos pixels de perfil de curvatura para a bacia do Gigante e para os movimentos de massa.

Ao contrário do plano de curvatura, o perfil de curvatura é representado na bacia do Gigante, em sua maioria, pelos formatos côncavos seguidos pelos convexos e por último os retilíneos (Tabela 7). Apesar disso, nas áreas dos movimentos de massa a predominância das formas côncavas também se mantém, porém, a relação de grandeza entre perfis côncavos e convexos não mostra grande diferença, sendo os valores de concavidade apenas 9,05\% superiores aos valores convexos. Isso mostra que mesmo com maior representatividade, as formas côncavas dos perfis de curvatura não podem ser usadas para individualizar os movimentos de massa, já a distribuição dos pixels instáveis entre os planos de curvatura côncavo e convexo é muito equilibrada.

\begin{tabular}{ccc|cc}
\hline & \multicolumn{2}{c|}{ Bacia do Gigante } & \multicolumn{2}{|c}{$\begin{array}{c}\text { Movimentos de } \\
\text { massa }\end{array}$} \\
\hline & Pixels & $\begin{array}{c}\text { Porcenta- } \\
\text { gem (\%) }\end{array}$ & Pixels & $\begin{array}{c}\text { Porcenta- } \\
\text { gem (\%) }\end{array}$ \\
\hline Total & 64133 & 100 & 14335 & 100 \\
Côncavo & 33416 & 52,10 & 7379 & 51,48 \\
Convexo & 29787 & 46,45 & 6768 & 47,21 \\
Retilíneo & 930 & 1,45 & 188 & 1,31 \\
\hline
\end{tabular}

Felipe Costa Abreu Lopes., F., C., A. Santos., I.

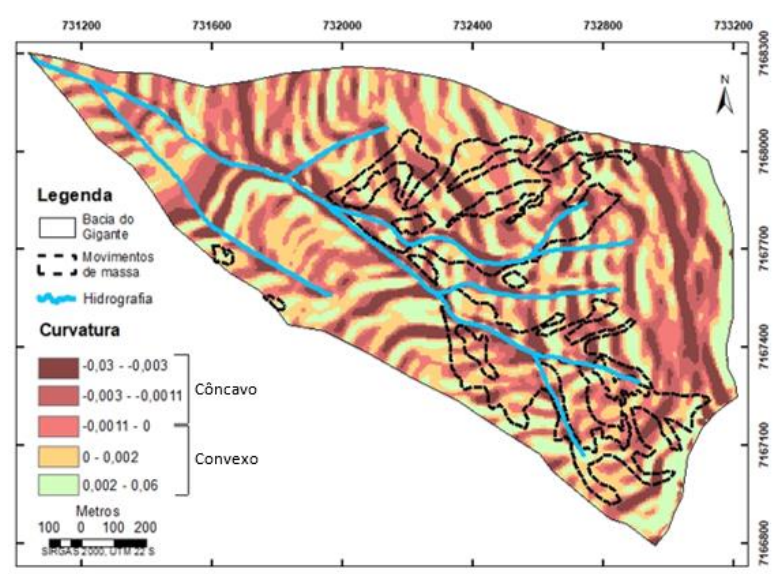

Tabela 7 - Relação entre perfil de curvatura na bacia do Gigante e nas áreas de movimento de massa.

Enquanto os planos de curvatura parecem representar melhor as áreas das cicatrizes dos movimentos de massa, os perfis de curvatura representam as áreas de acumulação de colúvio e rupturas de relevo. O primeiro aparece nos locais de perfil côncavo, onde juntamente com menor valor de declividade vai ter acumulação de sedimentos; o segundo está nos locais de transição para perfil convexo, onde o acúmulo de sedimento é menor e ocorre a exfiltração do escoamento subsuperficial.

Como exposto na revisão bibliográfica, notadamente nos trabalhos de Dietrich e Dorn (1984), Reneau et al (1987), Ohlmacher (2007) e Schulz et al (2008), as áreas de acumulação de colúvio vão ser fontes de material para os movimentos de massa, enquanto as áreas de ruptura de relevo terão exfiltração com consequente perda de estabilidade.

A representação das áreas de concentração de colúvio e rupturas de relevo (Figura 13) e sua análise de eficiência (Tabela 9) mostram uma evidente ligação com as cicatrizes de movimentos de massa. Os locais onde existem as duas feições intercaladas apresentaram instabilidade e movimentação, pois unem a acumulação de sedimentos fonte para os movimentos de massa com áreas de exfiltração de água facilitadora da instabilidade.

Locais onde houve o predomínio apenas de rupturas de relevo (perfis e planos de curvatura convexos) não apresentaram movimentos de massa, já que são locais com rochas expostas e menor concentração de material e possivelmente 
apresentam um solo mais raso, que pode estar, inclusive, na faixa de espessura imune (IIDA, 1999). Da mesma maneira, locais com predomínio apenas de concavidades têm declividades mais suaves e solos muito espessos, que vão sofrer

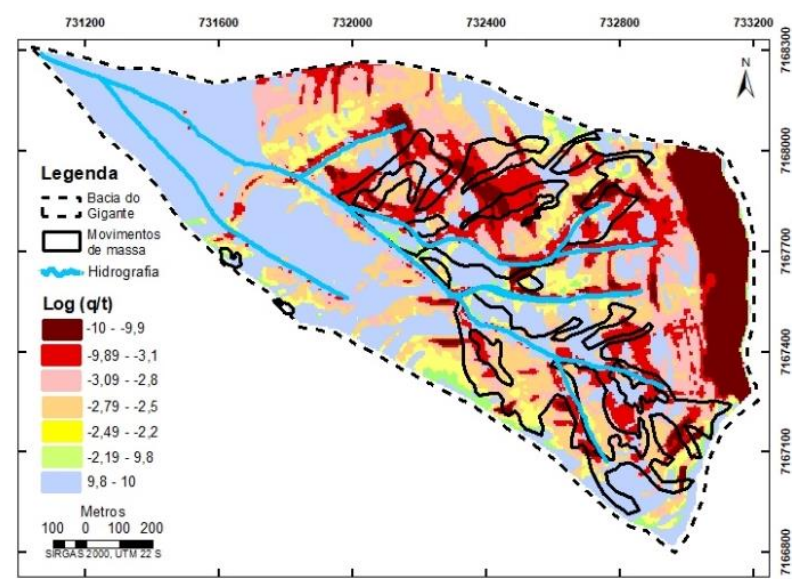

outros tipos de movimentações quando expostos a um grande volume de umidade.

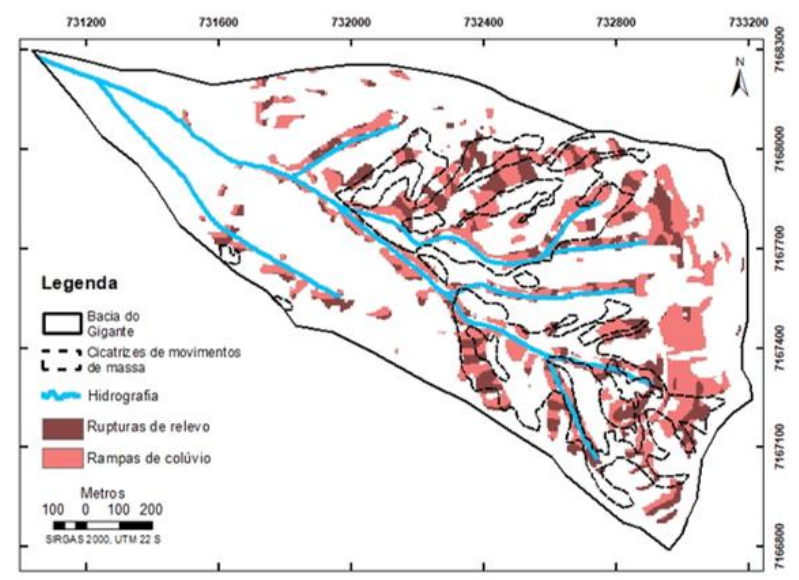

Figura 13 - Representação das áreas com concentração de colúvio e rupturas de relevo.

A relação entre as áreas de acumulação de sedimento e as rupturas de relevo obtidas a partir da combinação dos perfis e planos de curvaturas com o mapeamento de cicatrizes de movimentos de massa, foi analisada por meio de uma matriz de confusão (Tabela 9). A matriz de confusão mostra uma eficiência total de $71 \%$ das áreas de concentração de sedimentos e rupturas de relevo na identificação das cicatrizes, com apenas 29\% de erro total.

\begin{tabular}{cc|ll}
\hline Classe & $\begin{array}{c}\text { Eficiência da } \\
\text { classe }(E C)\end{array}$ & $\begin{array}{l}\text { Eficiência } \\
\text { total }(E T)\end{array}$ & $\begin{array}{l}\text { Erro } \\
\text { total }\end{array}$ \\
\hline
\end{tabular}

\begin{tabular}{cc|cc}
\hline $\begin{array}{c}\text { Áreas } \\
\text { instáveis }\end{array}$ & $41 \%$ & & \\
$\begin{array}{c}\text { Áreas } \\
\text { estáveis }\end{array}$ & $80 \%$ & $71 \%$ & $29 \%$ \\
\hline
\end{tabular}

Tabela 9 - Matriz de confusão mostrando a eficiência das rupturas de relevo e da concentração de colúvio em relação ao inventário de cicatrizes.

O resultado do modelo SHALSTAB (Figura 14) é expresso em $\log (q / t)$, onde ' $q$ ' representa a precipitação e ' $t$ ' a transmissividade do solo. Os menores valores correspondem às áreas mais instáveis da bacia. A classe com os menores valores $(-10-4,9)$ é classificada como incondicionalmente instável, enquanto a classe com os maiores valores $(9,8-10)$ indica os locais incondicionalmente estáveis.

Figura 14 - Simulação do modelo SHALSTAB para a bacia do Gigante e sua respectiva eficiência.

A análise visual do resultado permite perceber a concentração de áreas classificadas como instáveis dentro dos limites do inventário de cicatrizes, porém existem também grandes áreas tidas como instáveis que não estão inseridas nos limites do inventário. Da mesma maneira, áreas classificadas como incondicionalmente estáveis aparecem dentro do polígono das cicatrizes mapeadas.

$\mathrm{O}$ resultado da matriz de confusão para a simulação do SHALSTAB é mostrado na Tabela 10 e permite uma avaliação mais objetiva.

\begin{tabular}{cc|cc}
\hline Classe & $\begin{array}{c}\text { Eficiência da } \\
\text { classe (EC) }\end{array}$ & $\begin{array}{l}\text { Eficiência } \\
\text { total }(E T)\end{array}$ & $\begin{array}{c}\text { Erro } \\
\text { total }\end{array}$ \\
\hline $\begin{array}{c}\text { Áreas } \\
\text { instáveis }\end{array}$ & $49 \%$ & & \\
$\begin{array}{c}\text { Áreas } \\
\text { estáveis }\end{array}$ & $64 \%$ & $61 \%$ & $39 \%$ \\
\hline
\end{tabular}

Tabela 10 - Eficiência para a simulação do modelo SHALSTAB.

A partir da matriz de confusão nota-se que o modelo teve um acerto de $49 \%$ na classificação das áreas instáveis e de 64\% para as áreas estáveis. Este último acerto impulsionou a eficiência total do 
modelo para $61 \%$, com $39 \%$ de erros em seu resultado.

Cabe salientar que o resultado esperado de uma simulação não é $100 \%$ de acerto, tendo em vista as limitações dos modelos, que não incluem todas as variáveis ambientais em suas equações, e as incertezas devidas às generalizações envolvidas no processo de modelagem. A eficiência de determinado modelo também pode variar de acordo com o local onde ele foi aplicado e com a qualidade dos dados de entrada, o que faz com que o mesmo modelo possa ser eficiente para uma determinada aplicação e ter comportamento razoável para outra.

Todavia, na presente aplicação fica evidente que a eficiência no resultado do SHALSTAB poderia ter sido superior caso grandes áreas classificadas como instáveis, que estão fora do inventário de cicatrizes, fossem de alguma forma desconsideradas, por exemplo com o uso das formas da vertente. Isso mostra a relevância do uso das curvaturas como condição e contorno na aplicação de modelos.

Na ocorrência de movimentos de massa o plano de curvatura da vertente é fundamental para sua estabilidade, esses vão indicar o caminho preferencial do fluxo com a consequente acumulação de sedimento e uma melhor delimitação do contorno do movimento de massa, auxiliando na efetividade de seu mapeamento. Enquanto os perfis de curvatura, além de também evidenciar as áreas de acumulação de material para ser deslocado, evidencia as áreas de exfiltração de água responsável pela erosão, denominada por Tsukamoto e Minematsu (1987) de frentes de erosão, por Dunne (1980) e Gordon et al (2010) de erosão remontante e por Schulz et al (2008) como quebras de relevo, que em todos esses trabalhos são associados à instabilidade e ao desencadeamento de movimentos de massa. Os resultados da combinação dessas morfologias evidenciam a importância dessas características geomorfológicas na identificação de áreas propícias aos movimentos de massa e indica que sua integração aos modelos de simulação de instabilidade pode ser um caminho promissor.

\section{Conclusão}

A previsão de áreas instáveis é um desafio para qualquer gestor, pesquisador e modelo existente ou que venha a ser desenvolvido em decorrência do número de parâmetros e variáveis naturais envolvidas nesse processo e, também, pela relação caótica entre eles. Nesse sentido qualquer novo entendimento sobre o tema é um grande ganho para a ciência e para a sociedade.

Entre as diversas variáveis que influenciam na ocorrência de movimentos de massa, a declividade tem um papel de destaque, tanto na literatura quanto nos vários modelos desenvolvidos, porém outros fatores naturais têm grande influência sobre o equilíbrio das vertentes e devem ser usados para melhorar a eficiência das simulações de estabilidade.

A forma da vertente, tratada aqui como o conjunto de concentração de colúvio e rupturas de vertente, constitui avanço importante em relação ao mapeamento de áreas instáveis. Foi demostrado como os planos e perfis de curvatura côncavos, podem delimitar áreas de acúmulo de sedimento e ruptura de relevo e que sua aplicação em si já tem eficiência de $71 \%$ na delimitação de movimentos de massa. Esses valores estão significativamente acima da eficiência do modelo de estabilidade SHALSTAB, mundialmente usado para delimitar áreas instáveis e aplicado neste trabalho como base de comparação.

Áreas que apresentam acúmulo de sedimento intercaladas por rupturas de relevo tendem a apresentar movimentos de massa, isso porque a exfiltração da água na base da ruptura de relevo, além de resultar na erosão da área, favorece a saturação do colúvio a jusante, tornando-o menos estável. A partir disso pode-se concluir dois cenários na ocorrência de movimentos de massa:

1 - A erosão na base da ruptura de relevo pode tornar essa área instável fazendo-a deslizar sobre a o colúvio a jusante que, com peso extra, também se movimenta até encontrar declividades mais baixas capazes de estabilizar o material deslocado;

2 - A exfiltração de água na base da ruptura de relevo pode levar o material da coluvionar a jusante a um estado de saturação fazendo com que as camadas superiores do solo superem seu limite de estabilidade e desencadeiem seu deslocamento.

Sendo assim, destaca-se a importância da forma do relevo, representada pelos planos e perfis de curvatura, como condição de contorno da instabilidade de encosta. Recomenda-se que em estudos futuros estas variáveis sejam eventualmente incorporadas nas equações de 
modelos de estabilidade de encosta afim de refinar seus resultados.

\section{Agradecimentos}

Ao Departamento de Geografia da UFPR, à equipe do Laboratório de Hidrogeomorfologia e ao professor Irani dos Santos. À CAPES pela bolsa de pesquisa.

\section{Referências}

Barros, J. L., Tavares, A. O., Santos, P. P., Pereira, S., 2020. Região Centro de Portugal Continental: 150 anos de movimentos de vertente de origem hidro-geomorfológica. Comunicações Geológicas, 107, 123-127.

Bueno, K. E. M., Taveira, B. D. A., Lopes, F. C. A., Santos, I., 2015. Mapeamento e classificação dos fluxos de detritos na bacia do rio Jacareí - Serra do mar paranaense. Anais do XVI SBGFA, Teresina.

Chen, W., Pourghasemi, H. R., Kornejady, A., Zhang, N., 2017. Landslide spatial modeling: Introducing new ensembles of ANN, MaxEnt, and SVM machine learning techniques. Geoderma, 305, 314-327.

DOI: $10.1016 /$ j.geoderma.2017.06.020

Clerici, A., Perego, S., Tellini, C., Vescovi, P., 2006. A GIS-based automated procedure for landslide susceptibility mapping by the Conditional Analysis method: the Baganza valley case study (Italian Northern Apennines). Environ Geol, 50, 941-961.

Dai, F. C., Lee, C. F., 2002. Landslide characteristics and slope instability modeling using GIS, Lantau Island, Hong Kong. Geomorphology. Volume 42, Pag. 213-228.

De Rose, R. C., 2012. Slope control on the frequency distribution of shallow landslides and associated soil properties, North Island, New Zealand. Earth Surface Processes and Landform, 38, pag. $356-371$.

Dietrich W. E. e Dorn, R., 1984. Significance Of Thick Deposits Of Colluvium On Hillslopes: A Case Study Involving The Use Of Pollen Analysis In The Coastal Mountains Of Northen California. Journal of Geology. University of Chicago.
Dietrich, W. E., Reiss, R., 1995. A process-based model for colluvial soil depth and shallow landsliding using digital elevation data. Hydrological processes, 9, 383-400.

Dikshit, A., Satyam, N., Pradhan, B., 2019. Estimation of Rainfall-Induced Landslides Using the TRIGRS Model. Earth Systems and Environment, 3, p. 575-584.

DOI: $10.1007 / \mathrm{s} 41748-019-00125-\mathrm{w}$

Dunne, T., 1980. Formation and controls of channel networks. Progress in Physical Geography.

Effgen, J. F., Rocha, P. A., Pires, P. J. M., Marchioro, E., 2020. Parametrização geotécnica para modelagem de suscetibilidade a escorregamentos translacionais em Fradinhos, Vitória-ES. Soc. Nat., 32, p.711-727. DOI: 10.14393/SN-v32-2020-52656

Fernandes, N.F., Guimarães, R.F., Gomes, R.A.T., Vieira, B.C., Montgomery, D.R., Greenberg, H., 2004. Topographic controls of landslides in Rio de Janeiro: field evidence and modeling. Catena, 55, pag. 163-181.

Folador, R., 2015. Cálculo da probabilidade e quantificação do volume de material suscetível a escorregamentos - bacia do rio Jacareí, Morretes - PR. Dissertação de mestrado, Curitiba.

Freires, E. V.; Silva Neto, C. A.; Duarte, C. R.; Veríssimo, C. U. V.; Gomes, D. D. M.; Souza, A. E. P.; Silva, M. T., 2020. Influência de lineamentos estruturais no desencadeamento dos movimentos de massa no Maciço de Uruburetama, Ceará. Revista Brasileira de Geografia Física, 3, 1294-1308. DOI: 10.26848/rbgf.v13.3.p1294-1308

Gordon, L. M., Bennette, S. J. E Wells, R. R., 2010. Rill development, headcut migration, and sediment efflux from an evolving experimental landscape. 2nd Joint Federal Interagency Conference.

Gonzalez-Ollauri, A., Mickovski, S. B., 2017. Hydrological effect of vegetation against rainfall-induced landslides. Journal of Hydrology, 549, p. 374-387. DOI: 10.1016/j.jhydrol.2017.04.014 
Handwerger, A. L., Fielding, E. J., Huang, M.-H., Bennett, G. L., Liang, C., Schulz, W. H., 2019. Widespread initiation, reactivation, and acceleration of landslides in the northern California Coast Ranges due to extreme rainfall. Geophysical Research: Earth Surface, 124, p. 1782-1797. DOI: 10.1029/2019JF005035

Iida, T., 1999. A stochastic hydrogeomorphological model for shallow landsliding due to rainstorm, Catena, 34, p. 293313.

Intrieri, E., Carlà, T., Gigli, G., 2019. Forecasting the time of failure of landslides at slope-scale: A literature review. Earth-Science Reviews, 193, p. 333-349.

DOI: 10.1016/j.earscirev.2019.03.019

Kozciak, S., 2005. Análise determinística da estabilidade de vertentes na bacia do rio Marumbi - Serra do Mar - Paraná. Tese de doutorado, Curitiba.

Lopes, F. C. A., 2017. Análise de sensibilidade de variáveis e parâmetros de equações de fator de segurança. Anais do XVII SBGFA, Campinas, 2017.

Martins, T. D., Vieira, B. C., Fernandes, N. F., Oka-Fiori, C., Montgomery, D. R., 2017. Application of the SHALSTAB model for the identification of areas susceptible to landslides: Brazilian case studies. Revista de geomorfologie, 19, p. 136-144.

Masoumi, H., Jamali, A. A.., Mostafa, K., 2014. Investigation of role of slope, aspect and geological formations of landslide occurrence using statistical methods and gis in some watersheds in chahar mahal and bakhtiari province. Journal of Applied Environmental and Biological Sciences, 4, p. 121-129.

Meinhardt, M., Fink, M., Tünschel, H., 2015. Landslide susceptibility analysis in central Vietnam based on an incomplete landslide inventory: Comparison of a new method to calculate weighting factors by means of bivariate statistics. Geomorphology, 234, p. 8097. DOI: 10.1016/j.geomorph.2014.12.042

Meten, M., Prakash Bhandary, N., Yatabe, R., 2015. Effect of landslide factor combinations on the prediction accuracy of landslide susceptibility maps in the Blue Nile gorge of central Ethiopia. Geoenvironmental Disasters, 2, 1-17.

Montgomery, D. R., Dietrich, W.E., 1994. A physically based model for the topographic control on shallow landsliding. Water Resources Research, 30, p. 1153-1171.

Montgomery, D. R., Dietricj, W. E., Heffner, J. T., 2002. Piezometric response in shallow bedrock at CB1: Implications for runoff generation and landsliding. Water Resources Research, V.38, N.12.

Naidu, S., Sajinkumar, K. S., Oommenc, T., Anuja, V. J., Samuel, R. A., Muraleedharan, C., 2018. Early warning system for shallow landslides using rainfall threshold and slope stability analysis. Geoscience Frontiers, 9, p. 1871-1882. DOI: 10.1016/j.gsf.2017.10.008

Negrini, V., 2018. Variazione Del Rischio Frana Nel Bacino Alpino Del Comune Di Bormio. Dissertação de Mestrado, Milão, Politecnico Di Milano.

Ohlmacher, G. C., 2007. Plan curvature and landslide probability in regions dominated by earth flows and earth slides. Engineering Geology, 91, p. 117-134.

Pourghasemi, H. R., Rahmati, O., 2018. Prediction of the landslide susceptibility: Which algorithm, which precision? Catena, 162, p. 177-122.

DOI: 10.1016/j.catena.2017.11.022

Prakash, N., Manconi, A. e Loew, S., 2020. Mapping Landslides on EO Data: Performance of Deep Learning Models vs. Traditional Machine Learning Models. Remote Sens., 346, p.1-24. DOI:10.3390/rs12030346

Quevedo, R. P., Guasselli, L. A., Oliveira, G. G., Ruiz, L. F. C., 2019. Modelagem de Áreas Suscetíveis a movimentos de Massa: Avaliação Comparativa de Técnicas de amostragem, Aprendizado de máquina e modelos Digitais de Elevação. Geociências, 3, p. 781 - 795.

Regmi, N. R. e Walter, J. I., 2020. Detailed mapping of shallow landslides in eastern Oklahoma and western Arkansas and potential 
triggering by Oklahoma earthquakes. Geomorphology, no prelo.

DOI: 10.1016/j.geomorph.2019.05.06

Reichenbach, P., Rossi, M., Malamud, B. D., Mihir, M. Guzzette, F., 2018. A review of statistically-based landslide susceptibility models. Earth Science Reviews, 180, p. 60-91. DOI: 10.1016/j.earscirev.2018.03.001

Reneau, S. L., Dietrich, W. E., 1987. The importance of hollows in debris flow studies, examples from Marin County, California. Ver. Engineering Geology, 7, p. 165-180.

Rosi, A., Canavesi, V., Segoni, S., Nery, T. D., Catani, F., Casagli, N., 2019. Landslides in the Mountain Region of Rio de Janeiro: A Proposal for the Semi-Automated Definition of Multiple Rainfall Thresholds. Geosciences, 203, p. 1-15. DOI:10.3390/geosciences9050203

Schulz, W. H., Lidke, D. J., Godt, J. W., 2008. Modeling The Spatial Distribution Of Landslides-Prone Colluvium And Shallow Groundwater On Hillslope Of Seattle, WA. Earth Surface Processes and Landforms, 33, pag. $123-141$.

Sidle, R. C., Pearce, A. J., O'loughlin, C. L., 1985. Hillslope stability and land use, Washington.

Silveira, C. T., 2010. Análise digital do relevo na predição de unidades preliminares de mapeamento de solos: integração de atributos topográficos em sistemas de informações geográficas e redes neurais artificiais. Tese de doutorado. Curitiba.

Tabalipa, L. K., 2019. Aplicação do modelo SHALSTAB para o mapeamento de áreas suscetíveis a deslizamentos translacionais: estudo de caso em Jaraguá do Sul/SC. Dissertação de Mestrado, Florianópolis, UFSC.

Tsukamoto, Y. e Minematsu, H., 1987. Hydrogeomorphological characteristics of a zero-order basin. Erosion and Sedimentation in the Pacific Rim. Anais of the Corvallis Symposium.

Wang, D.J., Tang, H.M., Zhang, Y.H., Li, C. D., Huang, L., 2017. An improved approach for evaluating the time-dependent stability of colluvial landslides during intense rainfall. Environ Earth Sci., 8, p. 1-12. DOI:10.1007/s12665-017-6639-0

Wang, G., Sassa, K., 2003. Pore-Pressure Generation And Movement Of RainfallInduced Landslides: Effects Of Grain SizeParticle Content, Engineering Geology, vol. 69, pag. 109-125.

Whiteley, J. S., Chambers, J. E., Uhlemann, S., Wilkinson, P. B. and Kendall, J. M., 2019. Geophysical monitoring of moisture-induced landslides: A review. Reviews of Geophysics, 57, 106-145.

DOI: $10.1029 / 2018 R G 000603$

Zhang, Y., Chen, N., Liu, M., Wang, T., Deng, M., Wu, K., Khanal, B. R., 2019. Debris flows originating from colluvium deposits in hollow regions during a heavy storm process in Taining, southeastern China. Landslides, 1, p. 1-13. DOI 10.1007/s10346-019-01272-x

Zhao, C., Lu, Z., 2018. Remote Sensing of Landslides-A Review. Remote Sens, 279, p. 1-6. DOI:10.3390/rs10020279 